\title{
Academic/Digital Work: ICTs, Knowledge Capital, and the Question of Educational Quality
}

\author{
Jan Fernback
}

\author{
Temple University, Philadelphia, United States, fernback@temple.edu
}

\begin{abstract}
The ideology of the information society has transformed the performance of academic duties within higher education through the permeation of information and communication technologies (ICTs) into all aspects of the university. These technologies provide a common ground upon which teaching, research, and administration fuse; but how have such arrangements affected the quality of academic work? This ideology functions through values, hierarchies, rewards and punishments, and surveillance that influence routine work. Using a critical orientation, this paper examines the transformation of the quality of the intellectual products and work processes of higher education in a North American context. It examines how the educational technology industry fosters a type of control over academic workers, inhibiting the individual labourer's pursuit of educational quality. Grounded in Foucault's concept of "disciplinary power" and in Freire's notions of critical consciousness, it suggests a community-centred approach toward building knowledge capital in higher education.
\end{abstract}

Keywords: ICTs, Higher Education, Academic Work

\section{Introduction}

The academic enterprise is undergoing a transformation - from open access journals to distance learning collaboratives to course management technologies - brought about by information and communication technologies (ICTs) and the ideology of the information society. This ideology proclaims a set of technologically-centric values epitomizing the power of capitalist logic to commodify all aspects of cultural and economic existence. It has its roots in information infrastructure investment policies in the Global North ${ }^{1}$ that prioritized technological developments centred on economic productivity rather than the public good. According to the ideology of the information society, market transactions satisfy needs for information and thus, any differences between knowledge, information or data are subsumed into "information" as a commodity. This ideology connects ICTs with the commodification of information and marketization, affecting institutional governance and culture, and informing the performance of academic duties within higher education. The process of scholarly review, the content of scholarly publication, and the educational enterprise have been transformed in light of new institutional relationships, global information flows, and capital structures enabled by new communication technologies. These new technologies provide a common and necessary ground upon which teaching, research, and administration all coalesce; but how have these new arrangements impacted the quality of each separate venture? How is educational quality shaped when the emphasis on information capital (as material goods to be leveraged in the marketplace) rather than knowledge "capital" (human experience, wisdom, and individual talent in

${ }^{1}$ For example, the National Information Infrastructure (NII) in the U.S. and the European Information Infrastructure (from the Global Information Infrastructure) in the European Union. 
the Freirean (1985) sense defines the contemporary higher educational mission? What are the implications of such arrangements for academic workers? Using a critical orientation, this paper examines the transformation of the quality of the intellectual products and work processes of higher education in a North American context: academic scholarship, instructional activities, and administrative arrangements. By examining the ways that ICTs have transformed the actual work carried out by academics, it suggests a grounded, community-centred approach to addressing issues of knowledge capital in contemporary higher educational environments. Of particular use is Foucault's concept of "disciplinary power" in which institutional arrangements dictate control through the normalization of a host of procedures with a minimum exercise of force (Foucault 1977). In educational institutions, social arrangements regarding the exchange of knowledge, information, work, and evaluation are nurtured through values, established hierarchies, rewards and punishments, and surveillance. These social arrangements in the academy are enabled by ICTs. Gradually, the performance of academic labour (defined here as the work product of the university) is not only informed by ICTs but is dependent upon them as they become intrinsic to the operation of higher education. This paper also uses Freire's (1985; 2005/1974) ideas about education as a reproduction of dominant power structures that may be challenged by the valuing of local, experiential knowledge and wisdom as a democratizing force. The argument is that the espousal of ICTs in higher education has created an ideology that exalts information capital in ways that discipline academic workers and de-value knowledge capital and the quality of teaching, research, and administration.

According to Garnham (2002), the ideology of the information society shapes educational policy debates by asserting that ICTs enhance traditional learning modalities. Yet, the reality proves the only enhancements are financial ones to the elites with vested interests in propping up that technocratic ideology. In full embrace of this ideology, course learningware, administrative support software, and online journal submission/review processes are labour-saving ICTs adopted in order to save money over time by ostensibly increasing productivity (Gruner et al. 2015; Garnham 2002). Following Garnham (2002), the ideology of the information society stresses the technologically novel and innovative within the educational sector. This stance is revealed within the parameters of a corporatized university governance system that seeks to exploit ICTs for increased worker productivity and to respond to neoliberal pressures to appear competitive in the "information society" (Jarvis 2001). Such governing practices value information capital (marketized information products) rather than knowledge capital (individually developed learning and wisdom). For example, globally branded courseware and database providers have created what might be considered a hegemonic need among colleges and universities to maintain, for their various constituencies, a basic appearance of capability in the contemporary information environment. They also create a need to maintain contracts with ICT providers and to hire IT workers to troubleshoot courseware or database problems.

The global economy has embraced the ideology of the information society, and the academy apparently cannot be left behind. That hegemonic assumption means that scholarship, teaching, and administration are all transformed, in terms of quality, by the ICT revolution. The educational mission becomes indivisible from the ideology of the information society when ICTs are relied upon in the institutional arrangements, processes, and management of higher education. Within higher education, quality (following Cheng 2016) is not about managerial control, compliance, and bureaucracy. In teaching, research, and administration, quality is a "virtue of professional prac- 
tice" wherein the self-motivation to learn, teach, and work is the objective and noninstrumental pursuit of the excellence worthy of higher education (Cheng 2016, x-xi). Through a critical stance toward the marketization of ICTs, this paper explores how the educational technology industry operates to promote a disciplinary power over academic workers, thus impeding the individual labourer's pursuit of educational quality or Freirean (1985) transformation.

\section{ICTs and the Purpose of the University}

As ICTs became integrated into the higher educational landscape during the late 20th century, utopian and dystopian discourses began characterizing the new environment. Among the critical voices were those wary of the imposition of technologies onto what was assumed to be semi-autonomous ventures in teaching, research, and creative work. Notably, David Noble (1998) outlined the corporate takeover of universities through online education and other "automated" technologies in a regressive movement toward mass production. Others (Hamilton 2016; Jarvis 2001; Robertson 2003) argue that commercial interests are corporatizing the university so that knowledge is commodified, societal and individual interests in higher learning are subjugated, and managerialization increasingly typifies academic values.

These trends are evident in contemporary approaches to scholarship, teaching, and administration. New journals and corporate, transnational scholarly databases offer masses of information about which active scholars must stay informed. Students expect ICTs in the learning environment, but is there a coercive element to the use of these technologies? Do they enhance learning at the expense of validity or wisdom? Administrative ICTs may (or may not) increase organizational efficiencies, but compliance with them is enforced through hierarchical means, including resource allocation or expense reimbursement. What might be the individual and institutional costs for these imperatives?

Traditionally, and ideally for the Global North, the purpose of university education, is to develop, build upon, and transmit reasoned intelligence to future generations and to society at large. This involves helping students to foster critical judgment and analytical aptitude in order to provide education for professional careers, citizenship, and stewardship of human knowledge. For Freire (1985), education is about realizing human potential. There is a purity of purpose - education for the public spirit, according to Bowles and Gintis (2011) - that was not to be sullied by the discourse of free enterprise. The purpose of education shifts with time and space, but capitalist imperatives consign universities to the logic of the public sector rather than the public good (Bowles and Gintis 2011). While the ideology of the information society informs the performance of academic duties within higher education, the performance of academic work itself becomes dependent upon ICTs. This means that work undertaken in the academy - the tangible actions by faculty to produce outcomes (the performance of teaching, research, and service) - is enmeshed with the imperatives of the ideology of the information society. ICTs are now fundamental to the operation of higher education. Foucault's (1977) concept of disciplinary power is useful in understanding how.

\section{Disciplinary Power and Educational ICTs}

Foucault argued that discipline, as a mechanism of power, grew from 17th and 18th century practices which increased the scale of domination enacted on individual bodies to include "a subtle coercion, of obtaining holds upon it at the level of the mechanism itself - movements, gestures, attitudes, rapidity; an infinitesimal power over the 
active body" (Foucault 1977, 137). Discipline expanded the political body through institutional requirements that individual bodies be observed, trained, or otherwise manipulated in order to function in new economic, political, or institutional arrangements (Foucault 1977). The ideology of the information society mandates that capitalist cultures are conserved through technological means which commodify products or services in the market economy. Structures of educational governance which respond to market imperatives therefore require the implementation of educational ICTs to satisfy such imperatives to maintain legitimacy as purveyors of education as a product. Such institutional arrangements discipline faculty through accountability regimes (which Strathern (2000) refers to as "audit culture") that erode autonomy and compound workload. Information technologies are disciplinary in that they are a modality of power enacted on individual bodies for the purposes of expediency. They embody, consistent with Foucault (1977), a rationality giving rise to new norms of worker conduct and professional performance which conjoins faculty to the audit culture. The exercise of power is evident in the surveillance, training, and examination capabilities of information technology, and in the inevitability of its use. The disciplinary power inherent in academic technologies serves to regulate the behaviour of the faculty through the organization of space (the rigid, proscribed architecture of ICT systems) and through behavioural requirements (the mandatory use of universitybranded ICTs).

Disciplinary behaviour is enforced through surveillance mechanisms within the structure of university ICTs, such as accreditation, time logs and "effort reporting" systems. Based on Bentham's conception of the panopticon, a prison architecture allowing all subjects to be monitored by a single, unseen entity, Foucault (1977) notes that prisoners discipline themselves since they are unsure exactly when they are being watched. Supervisors are subject to surveillance from the outside as well (from governments, trustees, donors) and ultimately regulate themselves. Because disciplinary power operates diffusely and opaquely and impacts virtually every aspect of life, it is an efficient form of power that is nearly impossible to defy. Thus, ICTs perform surveillance activities both inside and outside the university; they monitor individuals working at jobs, and they monitor themselves via system logs or selfmonitoring, reporting and analysis (SMART) ${ }^{2}$ technologies.

Here is a link between Foucault's disciplinary power as it applies to academic ICTs and Taylor's theories of labour efficiency. Similar to disciplinary power's reliance on hierarchical observation, surveillance, and normalization, Taylorist principles stressed "scientific management" of the workplace through time/effort measurements, rigid divisions of labour, and hierarchical management techniques (Taylor 1911). Although Taylor's principles were geared toward improved productivity through worker efficiency, control over the workforce became centralized. Taylor describes "soldiering" $(1911,13)$ as a phenomenon whereby workers labour in accordance with the slowest among them - a practice that decreases efficiency while disincentivizing employees to work any harder. According to Braverman (1974), Taylorism deems technology to be a means toward productivity in that it facilitates control of the capitalist labour force by redistributing the sum of worker knowledge toward management. Technology, for Taylor, allowed work to become automated, thus "freeing" workers for unemployment or for non-skilled labour.

2 See: http://www.pcguide.com/ref/hdd/perf/qual/featuresSMART-c.html and "Hard Disk SMART Drives," https://www.pctechquide.com/hard-disks/hard-disk-smart-drives for an explanation of SMART. 
Globally branded courseware is an ICT meant to liberate academics for other types of labour (or to become irrelevant) as courses become automated. These forms of ICTs are valued not as knowledge capital but as time/labour-saving devices. For example, universities provide tutorials on creating video lectures - how to create them and how to make them "engaging." 3 The creation of these engaging video lectures is a form of uncompensated work for the university when the effort expands beyond contractual work obligations. For instance, the Idaho State University workload document ${ }^{4}$ states that faculty receive extra monetary compensation (up to $\$ 1,000$ ) or "workload credit" "if time is available" when teaching courses with "internet-based" components. This policy is an acknowledgment that the effort is not within the normal scope of work but that the faculty member's asset of "time" may not be available for remuneration. In-person lectures cannot be commodified or marketized to the extent that video lectures can (in MOOCs or expensive "great courses" online). This type of profit maximization creates possible additional revenue streams for universities on the back of uncompensated faculty effort. Additionally, Conceição and Lehman (2010) found that faculty overwhelmed by increased institutional demands on time when teaching online resorted to using strategies that I argue diminished the quality of their work, such as grading shortcuts, reliance on test banks, and assigning group work.

In Foucauldian terms, these supplementary video lectures are a normalized type of discipline that measures "the constraint of a conformity that must be achieved" (Foucault 1977, 183) and can be used "in the standardization of industrial processes and products" (184). The university community, in general, does not question the routinized practices emanating from the implementation of these technologies without being perceived as Luddites. The process of routinization and normalization is achieved in part through the claim that ICTs are essential for contemporary work in higher education - and, indeed, for the functioning of the university and its educational mission (see Glen 2008). For example, U.S. universities require the use of ICTs for course enrolment, grade reporting, budgeting, research grant submissions, "effort" reporting, and other functions. Thus, Taylorist notions of efficiency and standardization in service of financialization epitomize disciplinary power over faculty bodies by normalizing the technocratic ideology of the information society - ICTs save time and money, enhance learning, and reassure external constituencies (parents, governing bodies, regulators/accreditors) that universities are technologically savvy and leading-edge.

This ideology is exhibited in the discourses of 1990s higher education reform in the U.S. (Twigg 1996). In a roundtable of higher education policymakers and experts (lbid.), American higher education was cited for needing to provide more research, training, and teaching - more "productivity" - in the face of dwindling resources. The assumption that instructional software is necessary to increase faculty productivity undergirds the roundtable's claims that this "productivity problem" exists and that it affects educational quality and, more importantly, cost:

Controlling costs means reducing the direct, personal intervention of faculty where possible in the teaching and

\footnotetext{
${ }^{3}$ See, for example: https://www.rit.edu/academicaffairs/tls/course-development/creatingvideos, https://cft.vanderbilt.edu/guides-sub-pages/effective-educational-videos/\#engage, http://teaching.temple.edu/edvice-exchange/2016/03/6-tips-creating-engaging-videolectures-students-will-actually-watch

4 See: http://www2.isu.edu/ctech/faculty staff/Workload-Policy.pdf (Page 4)
} 
learning process. [...] One should expect that additional students could be accommodated at lower cost with technology than with traditional teaching methods. [...] In today's academic culture, responsibility for content rests with the faculty. But a shift is occurring in higher education where increasingly the institution is, in a sense, buying content which it can control. (Twigg 1996)

In this roundtable, educational quality is conceptualized in terms of efficiencies of cost and course delivery. A Foucauldian consideration of the faculty member's position in Twigg's scheme indicates a disciplining of the individual through standardization of knowledge production ("content") that the university purchases, further excluding faculty from defining quality within their own teaching. Faculty become purveyors of information capital (in Twigg's scheme by controlling costs through the purchase of content) at the expense of knowledge capital (wherein faculty are coerced into diminishing their pursuit of human knowledge and wisdom).

Similarly, Massy and Zemsky (1995) address the "productivity problem" by imposing onto higher education an economic model of "activity-based costing," which is the parsing of faculty labour into discrete modules in order to improve the ratio of capital cost to labour cost. The modules of faculty labour include classroom instruction, assessment, preparation, and meetings. Such activities can be performed by courseware that grades student work, presents video lectures, and monitors student progress. Unbundling these activities purportedly supports independent learning among students. Here faculty are conceived as an "unproductive" hindrance to student learning and are thus disciplined via ICTs through not only the standardization of faculty work efforts but through the exclusion of faculty creativity and input in the learning process. Massy and Zemsky further assert:

[T]echnology provides more flexibility than traditional teaching methods once one moves beyond minor changes that can be instituted by individual professors. The "career" of a workstation may well be less than five years, whereas that of a professor often exceeds 30 years. Workstations don't get tenure, and delegations are less likely to wait on the provost when particular equipment items are "laid off." The "retraining" of IT equipment, [...] is easier and more predictable than retraining a tenured professor. Within limits, departments will gain a larger zone of flexibility as the capital-labour ratio grows. (1995)

Such "piece labour" echoes Taylorist notions of ceding control to management. Furthermore, faculty are disciplined by homogenizing the faculty body and comparing them to IT equipment. The implication for educational quality is that "workstations" can provide an equally valuable, more "predictable" product at a lower cost. The recommendations put forth by Twigg (1996) and Massy and Zemsky (1995) not only became ingrained into higher education over the past two decades, but they also signalled the exponential rise in the educational technology market. Moreover, the assumption that ICTs will alleviate higher education's "productivity problem" has bur- 
geoned into a larger discourse of markets, knowledge capital, and technological efficiency. This discourse is normalized across higher education in the Global North.

Far from merely influencing the pedagogical mission of the university, the infiltration of ICTs as cost and labour-saving devices has spread to every function of the academy. Course management software, administrative software, and online journal submission/review processes have been adopted to save money with little evidence of effectiveness. Workloads of faculty and administrators have increased as a result of the technological standardization of procedures; what was the domain of support staff has now become the domain of faculty and administrators at the expense of support staff jobs (Gruner et al. 2015). Massy and Zemsky (1995) admit that "faculty might take over duties now performed by staff" (e.g. filling out forms). Hall $(2013,59)$ argues that such surplus academic work is often enacted online, not counting as classroom hours but rather as administrative effort. The normalization of this process eases the surveillance of academic staff, particularly through the use of effortreporting software (the technological version of "time logs"). Part of the innovative potential of Foucault's discipline as a device of power is the classification of individuals into organized categories - types of prisoners, patients, or students - to develop refined subdivisions of space and time (Foucault 1977, 144-149). Massy and Zemsky's (1995) technological schema serves to discipline the faculty member in Foucault's terms: "[S]pread out in a perfectly legible way over the whole series of individual bodies, the work force may be analysed in individual units. At the emergence of large-scale industry, one finds, beneath the division of the production process, the individualizing fragmentation of labour power; the distributions of the disciplinary space often assured both" (Foucault 1977, 145). The assumption that time/labour saving ICTs operate as a means of faculty empowerment is suspect; academic workers often have no choice but to operate within the confines of the arena set up by the technologies themselves. This means that power is not equally distributed; rather, power tends to be concentrated in the hands of the ICT companies and with those entities that support, own, and administer them (e.g., courseware companies). No individual academic can mimic the efficiency, focus, or speed of ICTs. Yet, the costs of labour-saving ICTs have been amplified by an entire ecosystem that has grown around the development, sale, training, and support of such ICTs.

Some academic work activities that are outside the commercial sector, such as reading student work, personal interactions with students and colleagues, peer review, and even administrative meetings, become commercialized when undertaken within the sphere of educational ICTs. In part, this is due to the exercise of disciplinary power through a naturalized conceptualization of these technologies as necessary, useful, and desirable. The idea that the institutional changes enabled by these ICTs serve the interests of individual faculty, administrators and students is ultimately hegemonic, and it is supported by capitalistic discourses accompanying the spread of academic ICTs. These discourses are examined next, within the context of the ideology of the information society and in terms of Freirean notions of quality and Foucauldian notions of disciplinary power.

\section{Discourses of Capital, Technology, and Profit}

In their discussion of "cognitive capitalism" and its significance for educational policy analysis, Peters and Bulut (2011, XxV-xxxiii) claim that knowledge production (amid other forms of immaterial production) is an enmeshment between humans and machines that result in a new form of capitalism and human subjectivity. This new formulation is flexible and "informationalized" in that the reliance on web technologies 
for the growth of global capitalism has heralded digital labour practices and the production of symbolic capital. What this means in the educational sector is that knowledge production becomes centred around distributed, open knowledge and learning structures that are supported by market mechanisms. These include networked knowledge portals and databases "where notions of individual performance have become global networks of labour governance where the traditional divisions between capital and labor are blurred" (lbid., xxxiii). Based on Peters' and Bulut's claims as well as Foucault's conceptualization of disciplinary power, I argue that the activities, processes, and products of academic work are constrained by, dictated by, and shaped by globally branded software products. As a result, educators' efforts to enact a Freirean (2005) "critical consciousness" - wherein students recognize sociopolitical incongruities and gain knowledge and wisdom from this recognition - suffer.

The corporatization of academic labour is reflected in the discourses of industries and organizations designed to support contemporary higher educational activities involving ICTs. Some examples of these discourses are included here from two major sources. First, EDUCAUSE, a non-profit organization that manages the edu internet domain, has a mission to "advance higher education through the use of information technology." 5 Second, Blackboard, an educational technology company owned by the private equity firm Providence Equity Partners, bills itself as "education's partner in change" with a mission to "to partner with the global education community to enable student and institutional success, by leveraging innovative technologies and services."6

Current policy initiatives for EDUCAUSE focus in part on accountability through university credentialing so that the U.S. might "maintain and advance its status as an economic world leader [...] with technology assuming center stage." In partnership with EDUCAUSE, corporate members serving the higher education IT market can "maximize brand awareness" and earn "value" for companies "through interaction with higher education decision makers [...] and the opportunity to take advantage of an expanding array of marketing options designed to maximize customer reach and visibility."7 These rhetorical exhortations make clear the agency of universities and their political advocates within the flows of global capitalism. Seeking partnership with corporate entities, U.S. higher education is positioned within global markets to compete, in entrepreneurial roles, for profit through the creation of new revenue streams. EDUCAUSE's policy position on intellectual property, for example, is that universities should be empowered to "more easily and more competitively transfer research innovations into the commercial sector." 8 As noted earlier, distance learning initiatives are another area of monetization of the information capital accumulated and stored in the university sector through the use of an array of IT products marketed as time/laboursaving devices while actually increasing academic work since automation suggests the possibility of higher teaching loads. Nowhere in these policy statements is a recognition of educational mission or quality. Who are the "customers" that EDUCAUSE and its partners serve? Is the purpose of a university to provide "research

${ }^{5}$ Educause Mission and Organization. https://www.educause.edu/about/mission-andorganization. Accessed February 26, 2017.

6 "About Blackboard." http://www.blackboard.com/about-us/index.aspx. Accessed March 10, 2017.

${ }^{7}$ https://www.educause.edu/about/corporate-participation/membership. Accessed February 23, 2017.

${ }^{8}$ https://www.educause.edu/focus-areas-and-initiatives/policy-and-security/educausepolicy/issues-and-positions/intellectual-property. Accessed March 25, 2017. 
innovations" for the commercial sector? The centrality of capitalist rhetoric in EDUCAUSE's policy position indicates the Foucauldian normalization of such discourses within higher education. The historical conditions (increasing consumerist, technocratic orientation toward higher education), the power relations (university governance structures that mimic corporate ones), and assumptions (including the sanctioning of Taylorist notions of worker efficiency and technological solutions) have converged to promote the hegemony of the ideology of the information society within higher education.

Blackboard learningware has become part of the higher educational landscape in many universities in North America and Europe. Purchasing Blackboard's products are justified in part by administrative rhetoric of cost containment and value extraction. According to a report, Big Data Has Arrived, produced by Blackboard in conjunction with survey data from The Chronicle of Higher Education (Rubley 2016, 5), administrators report a "substantial" return on investment in learning management systems. But, they claim, "institutional analytics, which seek to improve business practices" have been prioritized over learning analytics, "which seek to improve student success" (Ibid., 7). The Taylorist logic inherent in this report illustrates the technological dictates under which most higher educational institutions function. To appease external constituencies steeped in the discourses of ICTs as eradicators of higher educational bloat, a growing sector of university administrators with monopolies of knowledge manage the systems upon which institutions have become dependent to function pedagogically. Administrative positions conceived around these monopolies of technological knowledge conforming to specific systems have flourished (Tuchman 2009). Entire industries have emerged around courseware application development (add-ons), material sales (webinars, custom training), and staff hires for newly created learningware management positions. One of Blackboard's ${ }^{9}$ webinars highlights what have become hegemonic discourses of educational capitalism:

The Skills to Performance program at Bellevue is a unique model focused on higher order skills that translate to success in industry. The program is designed to drive learning outcomes based on the performance expectations defined by industry while recognizing the varying skill levels of students and architecting paths for them to achieve success. Through a unique public-private partnership with Blackboard, Bellevue has differentiated the learning experience in a way that is intended to attract more students looking for a competitive edge and connects more tightly with the skills that the workforce partners value.

The webinar itself is a product of the drive to monetize various educational products, and simultaneously, the rhetoric of technological capitalism is infused into the webinar's content. The learning goals of the Skills to Performance program are "defined by industry" rather than any goals for individual enrichment or knowledge capital. The program seeks students looking for a "competitive edge" within the strictures of company-defined skill-sets. Such discourses are normalized throughout higher education as a form of disciplinary power. Foucault $(1971,19)$ argued that education "follows

\footnotetext{
${ }_{9}^{9}$ Planning a Workforce Needs Program. http://bit.ly/2srWCDH. Accessed February 23, 2017.
} 
the well-trodden battle-lines of social conflict. Every educational system is a political means of maintaining or of modifying the appropriation of discourse, with the knowledge and the powers it carries with it." By acknowledging the place of the educational institution within a nexus of socio-political discourses of power, it seems that webinars such as these are a response to the market conditions and external pressures to which higher educational administrators are compelled to conform. Finally, the ideology of the information society is upheld through the alterations in knowledge and practices emerging from the normalization of discourse artefacts which previously seemed unrelated - such as ICTs and higher education into market-driven webinars.

Three tendencies, following Cantor and Courant (2003) and McCarthy (2011), characterize the "enterprise ethic" that epitomizes contemporary universities: virtualization (operating the university as an online entity), vocationalization (expecting an industrial return on educational investment), and fiscalization (departmental viability as measured by budgetary means). Together, these tendencies, according to McCarthy (2011) create configurations that erode community, privilege an instrumental rationality underlying discourses of market logic in universities, and favour profit motives that govern university operations (including the investment in time/labour-saving technologies) and influence faculty research agendas toward collaborative efforts with industry. In such configurations, skills and information replace knowledge and wisdom as educational products. Disciplinary power and imperatives toward efficiency that are evident in these technological discourses demonstrate the ascendancy of global market capitalism in universities that may repurpose the overall quality of education, research, and administration itself away from professional excellence and toward managerialization. The emphasis on using ICTs for strategic planning, information acquisition, and market-friendly assessment (what Freire (1985) warns against) results in the de-emphasis on curricula that cultivate the public good - humanistic inquiry, philosophy, civic engagement, critical inquiry - in favour of vocational education. Content management is emphasized through bureaucratic requirements that don't serve the ideal, democratic purposes of the university. According to Cheng (2016), the prominence of bureaucratic, managerial ideas about "quality" in higher education minimize the true concept of quality as a "virtue of professional practice" (Ibid., $x$ ) that advances academics' values and commitment to excellence in teaching, research, and administration.

The use of ICTs in service of capitalistic rationality means that more work effort is offloaded onto faculty. Administrative services once performed by office managers are now performed by the faculty labour force, aided by all manner of software products designed to create "efficiencies" in expense reimbursement, budget management, travel arrangement, time/effort logs, scheduling, grant application submission, and ancillary course preparation (e.g., interaction with library personnel or "recycling" materials in courseware applications). The logic of such processes and standards goes unchallenged. For Hall $(2014,828)$, the technological, capitalistic orthodoxy dominating higher education means that "the productivity of the academic can be measured against her peers through the socially-necessary labour time that determines what her productivity should be" so that collaborative efforts within the academy become discouraged in favour of competition dictated by marketization. According to Cantor and Courant $(2003,6)$, "excessive concentration on profitability and businesslike behavior may lead to the underproduction of the public goods that make [universities] different from and more than a collection of smart folks each doing his or her own thing." As a result, they argue that universities forget to create a diverse 
campus community, preserve and rely upon past wisdom, sustain campus cultural groups (museums, gardens), and encourage interdisciplinarity and non-profitable endeavours. These arguments ground my claims that the ideology of the information society may be critically challenged by community-centred academic work strategies that value knowledge capital.

The ideology of the information society has created capitalist discourses of educational technology that devalue quality in the face of Taylorist efficiencies and Foucauldian surveillance and discipline. The academy is a community which is fragmented by the pursuit of information capital in accordance with the ideology of the information society, and the forces of global capitalism have prioritized discourses about the value of technical and scientific rationality. The language of learning and teaching has changed to resemble the language of business. "Content management" supplants well-theorized and communicated scholarship. The wisdom of past experience, critical ability, and context are underplayed. The mechanisms of Foucault's disciplinary power succeed in making these realities seem normal. But more than 20 years beyond the predictions of Massy and Zemsky (1995), machine grading is still suspect, and the analytical writing portion of the GRE exams is scored by human labour. ${ }^{10}$

Foucault's explication of disciplinary power and normalization of routine practices shows that the technologies of higher education's "audit culture" (Strathern 2000) are vehicles for a type of rationality that sanctions governance based on a subjectivity of individuals who have no choice but to become "auditable." Although Foucault is sometimes criticized for a lack of solutions in praxis and the belief that educational institutions merely reinforce structures of power and dominance, his understanding of disciplinary power provides a starting point, with Freire, toward some concrete strategies of resistance among academic workers. According to Foucault (1972/1980, 133), the role of the intellectual is to act within the community to produce change - to use ideas to spur action - thus "detaching the power of truth from the forms of hegemony, social, economic and cultural, within which it operates". Freire's (1985) critique of education stems from the hierarchical and authoritarian characteristics of schooling that both learners and teachers can resist through "critical consciousness" (Freire 2005/1974). This process liberates them from oppression through community discourses of reflection on lived experiences. Foucault's diagnoses of power arrangements can combine with Freire's mission of critical consciousness to support community-centred resistance to the power relations manifested in higher education's embrace of the ideology of the information society.

\section{Responses to the Inevitability of ICTs in Higher Education}

Responses to the technological challenges to higher education can focus on building knowledge capital with the aid of existing ICT-centred arrangements. This paper suggests models for reconstituting academic ventures in ways that acknowledge the naturalized assumptions regarding the necessity of ICTs while simultaneously pursuing knowledge capital. We have seen how the discursive practices surrounding ICTs in higher education construct a milieu of knowledge/power that has become hegemonic. However, recalling that Foucault's concept of disciplinary power theorizes its enactment over docile bodies, the following models suggest a type of control over one's body as an academic worker. These models are offered as ways to assert freedom within an oppressive configuration of mandated technologies. Within aca-

\footnotetext{
${ }^{10}$ See: http://www.ets.org/gre/institutions/scores/how
} 
demic communities, new practices can emerge that emphasize quality as a "virtue of professional practice" (Cheng 2016) by using ICTs strategically and intelligently rather than conveniently. They include:

1. creating more open (visible) peer review systems that are communally based;

2. building collaborative teaching environments;

3. producing knowledge bases as a way of integrating teaching, scholarship, and administrative responsibilities.

These models are a means to provide academic workers, primarily full-time faculty, a measure of control within the scope of the ideology of the information society through community-based resistance. For Freire, resistance starts when faculty and students work together toward critical consciousness. He recognized power as a form of domination, silencing people through a dynamic of institutional power, ideology, and technology that demands critical consciousness for self-emancipation (Freire 1985). For Foucault $(2003,6)$, the power structures inherent in the educational system can be resisted through a critique at the local level. Foucault argues that institutional power is enacted in every interaction and can thus be challenged through interventions (Foucault 1997) of the type Freire advocates. He argues for the possibility of resistance, claiming "The idea that power is a system of domination that controls everything and leaves no room for freedom cannot be attributed to me" (Ibid., 293). In educational settings, resistance includes "ēthos, practices of the self and of freedom" (Ibid., 299). Ideas of resistance espoused by Freire and Foucault combine to create a framework for the models below.

\subsection{Community-Based Scholarly Peer Review}

Scholarly texts are produced and consumed by disciplinary communities, and ICTs are used to oversee submission and review and to control access to the products of scholarship. To take advantage of the repositories of knowledge within disciplines, scholarly peer review could use ICTs to add a new component to the traditional use of two or three anonymous reviews. This model would involve the embargoed draft article being posted to a communal review web site, organized by journal editors, for a limited time period during which pre-approved, anonymous "reviewers" would comment on the draft and the author could weigh in with responses. The burden on individual reviewers would be lessened by the efforts of the community, and the community gains a preview of new scholarship. Scholars would appropriate the technologies to emphasize knowledge capital, the scholarly exchange of ideas, and the progressive enrichment of documents. This process could occur on cooperative platforms designed outside the architecture of existing commercial ICTs in order to put the communal ethos of scholarly collaboration above corporate control of knowledge production. Digital platforms for communities of interest/practice can enable worker ownership, collective knowledge production, and democratic governance. ${ }^{11}$

Community-based peer review as a form of document enhancement allows for the discussion of ideas within the community as a social practice. This form of review permits a rich context for the document arising from greater understanding of relationships between disciplinary community structures and attendant intellectual products. The gradual refinement of the draft article becomes useful for knowledge capital

\footnotetext{
${ }^{11}$ For an explanation of platform cooperativism, see: http://platformcoop.net/about\#
} 
over the long term since it promotes the wisdom of communal knowledge building over the informationalization of scholarly products.

\subsection{Collaborative Teaching Environments}

A similar model can be developed for teaching in which ICTs are used to develop communal knowledge bases set up at individual universities for the faculty community to talk across and within disciplines about pedagogical strategies, theories, ideas, assessments, and curricula. Components can include knowledge banks enabled by courseware; virtual meetings at designated times within or external to the courseware; FAQs that are disciplinary in nature; and face-to-face meetings. The rewards of this arrangement are: intellectual exchange within a disciplinary community; new/multiple perspectives from interdisciplinary collaboration and conversation; an emphasis on knowledge capital; and potential time savings from not having to "reinvent the wheel" with new course preparations or testing new pedagogical strategies. Freire (1985) argues that pedagogy can challenge the hegemony of naturalized assumptions about the world through communities of practice that seek social change. For Freire, knowledge itself is a social process leading to transformative action, so knowledge bases can be a form of resistance through the above-mentioned rewards. In an educational environment where ICTs have become ingrained into all aspects of the academic venture, faculty can attempt to use those technologies to enact Freire's ethos in transformative ways.

\subsection{Community-Resourced Administration}

Economic conditions and regulatory oversight in universities have resulted in staff cutbacks that have created extra labour for faculty who lack the expertise and proficiency that staff trained in myriad technologies had developed (Gruner 2015). For faculty, this can mean incurring "considerable mental overhead in task-switching" (lbid., 4). But there are possibilities for communal knowledge bases to alleviate some of the administrative burden. In the absence of larger institutional change, groups of faculty and administrators can work collectively to develop repositories of instructions, examples, and shortcuts that empower the community to abate some of the most frustrating, alienating aspects of administrative requirements. As a means of resistance to the disciplinary power exerted within the sphere of institutional ICTs, Hall $(2013,73)$ suggests that academic labourers work toward "developing collective forms of work or doing that enables the development of discretionary power and autonomy beyond the rate of profit [...] to overcome the mechanisms that co-opt how that labour inside capitalism overcomes all of human sociability, to the point where all activity appears to be determined by economic growth." Knowledge bases are a form of collective knowledge capital that can offset the overburdening of academic labour at the expense of educational quality. Workload burdens on faculty are well documented (Ginsberg 2011; Conceição and Lehman 2010), and university governance structures add to that burden, but communal knowledge bases address Hall's (2013) invitation to faculty to work collectively toward a measure of autonomy.

These models are aimed at counteracting, within the boundaries of the possible, the corporatization and informationalization of the university at the expense of academic workers and students who are disciplined as docile bodies within an environment of global capitalist accumulation. Discord arises when compliance with institutional mandates to use specific ICTs interferes with the academic mission, and technological competency requirements siphon time from teaching and scholarly/creative activity. The worth of academic work shifts when capitalistic discourses, Taylorist 
principles, and Foucauldian discipline create new literacies of productivity, new modes of surveillance, and new politics of control.

\section{Conclusion}

Using a critical lens, this paper used a Foucauldian perspective to examine how ICTs, in service of the ideology of the information society, discipline academic workers, thus interfering with work quality or Freirean (1985) transformation. Tuchman (2009) argues in her examination of the marketization of higher education, that universities have become "auditable" - capable of being measured and disciplined. Such "coercive accountability associated with both an audit society and its culture helps to constitute an accountability regime; a politics of surveillance, control, and market management disguising itself as the value-neutral and scientific administration of individuals and organizations" (Tuchman 2009, 12). The accountability regime fostered by widespread institutional use of ICTs establishes faculty as objects of surveillance rather than as co-communicators. Audit culture (Strathern 2000) reveals a relationship of power between scrutinizer (administrative governance) and observed (faculty working within the configuration of educational ICTs). Because educational ICTs conform to the political systems under which they are instituted (the ideology of the information society) they promote the values of informationalization and marketization. Those values filter through the university culture at large, exerting a disciplinary control over faculty workers. Quality is diminished as a result, as faculty are overburdened by technocratic demands (Gruner et al. 2015) that encourage teaching shortcuts (Conceição and Lehman 2010) or inattention to research or creative agendas (Ginsberg 2011).

Acknowledging that faculty must work within the technological structures instituted by universities - and also acknowledging that some of those structures do enhance academic work - this paper suggests means of resisting the political-ideological realities of domination engendered in such environments. Recalling the ideal purpose of the university to build reasoned intelligence and to realize human potential (Freire 1985), a progressive environment for the advancement of knowledge capital must be prioritized. In part, this means valuing wisdom, thinking, communicating, and acting within the academic community to contest the informationalization of the university. Freire argued that education must consider the political and socio-economic context in which it occurs in order to implement critical consciousness. Within the ideology of the information society, Freire's mission to liberate and empower the politically marginalized must account for technocratic realities and respect community-centred models for resistance of disciplinary power.

Foucault $(2003 ; 1997)$ admonished his readers to consider the manifold qualities of power: that power may be constructive as well as exploitive; that power as well as resistance are everywhere; that resistance is power exercised under different conditions; and that freedom provides terrain for both power and resistance. Although neither Freire nor Foucault offered specific directives for resistance, both sought to problematize links between knowledge and power within institutional contexts. With this grounding, citizens of the academy can investigate ways to use information technologies to enrich non-informationalized and non-marketized scholarly exchange. Academic workers can collectively resist the oppressiveness of ICTs employed by educational institutions and use them to make universities into spaces for socially-useful knowledge and for enlightened politics. Educational ICTs do not have to be impediments to free, open inquiry in the university. They do not have to be impediments to knowledge capital as a public good. 


\section{References}

Bowles, Samuel and Herbert Gintis. 2011. Schooling in Capitalist America: Educational Reform and the Contradictions of Economic Life. Chicago: Haymarket.

Braverman, Harry. 1974. Labor and Monopoly Capital: The Degradation of Work in the Twentieth Century. New York: Monthly Review Press.

Cantor, Nancy and Paul N. Courant. 2003. Scrounging for Resources: Reflections on the Whys and Wherefores of Higher Education Finance. New Directions for Institutional Research 119: 3-12.

Cheng, Ming. 2016. Quality in Higher Education. Rotterdam: Sense Publishers.

Conceição, Simone C.O. and Rosemary M. Lehman. 2010. Faculty Strategies for Balancing Workload When Teaching Online. Presented at the Midwest Research-to-Practice Conference in Adult, Continuing, \& Community Education, Michigan State University, Lansing, Michigan, September 26-28.

Foucault, Michel. 2003. Society Must Be Defended: Lectures at the Collège de France, 19741975. New York: Picador.

Foucault, Michel. 1997. The Ethics of the Concern for Self as a Practice of Freedom. In Ethics: Subjectivity and Truth, edited by Paul Rabinow, 281-301. New York: The New Press.

Foucault, Michel. 1980/1972. Power/Knowledge. New York: Pantheon.

Foucault, Michel. 1977. Discipline and Punish: The Birth of the Prison. New York: Pantheon.

Foucault, Michel. 1971. Orders of Discourse. Social Science Information 10 (2): 7-30.

Freire, Paulo. 2005/1974. Education for Critical Consciousness. London: Continuum.

Freire, Paulo. 1985. The Politics of Education: Culture, Power, and Liberation. South Hadley: Bergin \& Garvey.

Garnham, Nicholas. 2002. 'Information Society' as Theory or Ideology: A Critical Perspective on Technology, Education and Employment in the Information Age. In Digital Academe: The New Media and Institutions of Higher Education and Learning, edited by William $\mathrm{H}$. Dutton and Brian D. Loader, 253-267. London: Routledge.

Ginsberg, Benjamin. 2011. The Fall of the Faculty: The Rise of the All-Administrative University and Why It Matters. New York: Oxford University Press.

Glen, Marie. 2008. The Future of Higher Education: How Technology Will Shape Learning. A report by the Economist Intelligence Unit, sponsored by the New Media Consortium. Accessed June 10, 2017. https://www.nmc.org/pdf/Future-of-Higher-Ed-(NMC).pdf

Gruner, Sol M., David Easley, Eric Giese, Tim Healey, Hening Lin, Michael Lenetsky and Paul McEuen. 2015. Report of the College of Arts and Sciences Committee on Streamlining Research Administration. Accessed April 1, 2017. https://blogs.cornell.edu/deanoffaculty/files/2016/11/Streamlining-Administration$1 \times 4 \mathrm{k} 5 \mathrm{pj} . \mathrm{pdf}$

Hall, Richard. 2014. On the Abolition of Academic Labour: The Relationship between Intellectual Workers and Mass Intellectuality. tripleC: Communication, Capitalism \& Critique 12 (2): 822-837. http://www.triple-c.at/index.php/tripleC/article/view/597

Hall, Richard. 2013. Educational Technology and the Enclosure of Academic Labour inside Public Higher Education. Journal for Critical Education Policy Studies 11 (3): 52-82.

Hamilton, Edward C. 2016. Technology and the Politics of University Reform: The Social Shaping of Online Education. Basingstoke: Palgrave Macmillan.

Hanley, Larry. 2002. Educational Technology and Academic Labor. The Radical Teacher 63: 25-28.

Jarvis, Peter. 2001. Universities and Corporate Universities: The Higher Learning Industry in Global Society. London: Kogan Page.

Massy, William F. and Robert Zemsky. 1995. Using Information Technology to Enhance Academic Productivity. Educomreg, Interuniversity Communications Council, Inc. Accessed March 15, 2017. https://net.educause.edu/ir/library/html/nli0004.html 
McCarthy, Cameron. 2011. Afterword: The Unmaking of Education in the Age of Globalization, Neoliberalism and Information. In Cognitive Capitalism, Education and Digital Labor, edited by Michael A. Peters and Ergin Bulut, 301-321. New York: Peter Lang.

Noble, David. 1998. Digital Diploma Mills: The Automation of Higher Education. First Monday 3 (1). Accessed March 3, 2017. http://www.firstmonday.org/ojs/index.php/fm/article/view/569

Peters, Michael A. and Ergin Bulut. 2011. Introduction. In Cognitive Capitalism, Education and Digital Labor, edited by Michael A. Peters and Ergin Bulut, xxv-xl. New York: Peter Lang.

Robertson, Heather-Jane. 2003. Toward the Theory of Negativity: Teacher Education and Information and Communication Technology. Journal of Teacher Education 54 (4): 280296.

Rubley, Julie Nicklin. 2016. Big Data Has Arrived: Using Technology to Measure Student Performance. Accessed January 14, 2017. http://www.blackboard.com/educationanalytics/resource/chronicle-survey-report.aspx

Strathern, Marilyn. 2000. Audit Cultures: Anthropological Studies in Accountability, Ethics and the Academy. London: Routledge.

Taylor, Frederick Winslow. 1911. The Principles of Scientific Management. New York: Harper and Brothers.

Tuchman, Gaye. 2009. Wannabe U: Inside the Corporate University. Chicago: University of Chicago Press.

Twigg, Carol. 1996. Academic Productivity: The Case for Instructional Software. A Report from the Broadmoor Roundtable, Colorado Springs, Colorado, July 24-25. Accessed February 27,2017 . https://net.educause.edu/ir/library/html/nli0002.html

\section{About the Author}

Jan Fernback

Jan Fernback is Associate Professor of Media Studies in the Klein College of Media and Communication at Temple University. Her current work examines issues of privacy and surveillance online and in mobile technologies, the impact of information/communication technologies on urban revitalization efforts, institutional uses of ICTs, and the meaning of virtual community in contemporary culture. She is the author of Teaching Communication and Media Studies: Pedagogy and Practice, published by Routledge. 